\title{
Role of blood cultures during continuous renal replacement theraphy in septic patients
}

\author{
JA Monsalve- Naharro ${ }^{1}$, P Cuesta-Montero ${ }^{*}$, E Domingo-Chiva² ${ }^{2}$ S Plata-Paniagua ${ }^{2}$, A López-Pérez ${ }^{3}$, \\ F Martinez-Lopez ${ }^{1}$, JM Jimenez-Vizuete ${ }^{1}$ \\ From ESICM LIVES 2015 \\ Berlin, Germany. 3-7 October 2015
}

\section{Introduction}

Adequate microbiological diagnosis through blood cultures $(\mathrm{BC})$ is essential to optimize the treatment of septic patients. However, their extraction in critically ill patients with continuous renal replacement therapy (CRRT) is poorly studied and characterized. CRRT can modify clinical signs of bacteriemia like fever and therefore the indication of obtaining BC. It is also unknown if the therapy itself can alter the results of $\mathrm{BC}$. The routine of $\mathrm{BC}$ extraction every 24 or 48 hours is controversial and could be harmful.

\section{Objectives}

To describe the results of blood cultures obtained during treatment with CRRT in septic patients with acute renal failure.

\section{Methods}

Observational retrospective study of a cohort of septic patients admitted to a critical care unit with acute renal failure who required CRRT. BC were extracted routinly or by medical criteria. The study period ranged from May until September 2011.

The variables collected were: positivity rate, contamination rate, microbiological agent most frequently isolated and temporary positivity ratio (more or less than 7 days).

We considered the recomendations of the Spanish Society of Infectious Disease and Clinical Microbiology to defne the contamination or positive $\mathrm{BC}$.

\section{Results}

33 patients were included (57,6\% males). Median of age was 66 years (IQR: 60-77). The diagnosis were: 23 septic shock (70\%), 8 severe sepsis (25\%) and 2 moderate

${ }^{1}$ Complejo Hospitalario Universitario de Albacete, Anesthesiology and Critical Care, Albacete, Spain

Full list of author information is available at the end of the article sepsis (5\%). The average score of APACHE II was 20,5. The mortality asociated was $40 \%$ (13 patients). 148 patients undergoing CRRT cycles were collected. 104 BC were obtained from 66 of these CRRT cycles. Microbiological results were: negative in $78 \mathrm{BC}(75 \%)$; 18 positive $\mathrm{BC}$ contamination $(17,3 \%$, coagulase negative Staphylococcus in all cases); 8 true positive $\mathrm{BC}(7,7 \%$, corresponding to 5 patients).

For these 5 patients, BC were collected 7 days after admission. The microbiological agents obtained in true positive BC were: Acinetobacter Baumanii and Staphylococcus epidermidis both in $3 \mathrm{BC}$ each one, and Pseudomonas Aeruginosa and Serratia marcencens in $1 \mathrm{BC}$ each one.

\section{Conclusions}

Rentability of $\mathrm{BC}$ in this cohort of critically ill patients with CRRT is low, and associated with more than seven days after admission. There was a high rate of contamination.

CRRT can alter BC results and modify their rentability. It is necessary to clarify the role of routine $\mathrm{BC}$ in patients with CRRTin the absence of signs of infection.

\section{Authors' details}

${ }^{1}$ Complejo Hospitalario Universitario de Albacete, Anesthesiology and Critical Care, Albacete, Spain. ${ }^{2}$ Complejo Hospitalario Universitario de Albacete, Pharmacy, Albacete, Spain. ${ }^{3}$ Complejo Hospitalario Universitario de Albacete, Albacete, Spain.

Published: 1 October 2015

\section{References}

1. Le Blanc L, et al: Intensive Care Med 2006, 32:1802-7.

2. Otto GP, et al: Infection 2013, 41:387-90.

doi:10.1186/2197-425X-3-S1-A59

Cite this article as: Monsalve- Naharro et al:: Role of blood cultures during continuous renal replacement theraphy in septic patients. Intensive Care Medicine Experimental 2015 3(Suppl 1):A59.

\section{SpringerOpen ${ }^{\circ}$}

(C) 2015 Monsalve- Naharro et al.; This is an Open Access article distributed under the terms of the Creative Commons Attribution License (http://creativecommons.org/licenses/by/4.0), which permits unrestricted use, distribution, and reproduction in any medium, provided the original work is properly cited. 